\title{
Auricular Acupressure in Patients with Hypertension and Insomnia: A Systematic Review and Meta-Analysis
}

\author{
Zhi-Hui Zhao, ${ }^{1}$ Yi Zhou, ${ }^{2}$ Wei-Hong Li ${ }^{\mathbb{D}},{ }^{1}{ }^{\text {Zhao-Hui Tang, }}{ }^{1}$ Ting-Wei Xia, ${ }^{1}$ and Han-Li ${ }^{1}$ \\ ${ }^{1}$ Basic Medical College, Chengdu University of TCM, Chengdu, Sichuan 611137, China \\ ${ }^{2}$ Hospital of Chengdu University of TCM, Chengdu, Sichuan 610072, China \\ Correspondence should be addressed to Wei-Hong Li; lwh@cdutcm.edu.cn
}

Received 29 January 2020; Revised 18 May 2020; Accepted 28 May 2020; Published 17 June 2020

Academic Editor: Ian Cock

Copyright (C) 2020 Zhi-Hui Zhao et al. This is an open access article distributed under the Creative Commons Attribution License, which permits unrestricted use, distribution, and reproduction in any medium, provided the original work is properly cited.

Objective. The efficacy of auricular acupressure in patients with hypertension and insomnia is controversial. This systematic review aims to explore the effectiveness of auricular acupressure in reducing blood pressure and improving sleep in this population. Methods. We conducted an extensive database search in Cochrane Central Register of Controlled Trials, PubMed, Ovid LWW, Web of Science, Chinese Biomedical Literature Database, China Knowledge Resource Integrated Database, Wanfang Data, and China Science and Technology Journal Database on randomized controlled trials published from inception to November 2019 that compared auricular acupressure with a control or comparison group on blood pressure control and sleep improvement. Two reviewers independently conducted data screening and extraction. Study quality was evaluated using the Cochrane Handbook for Systematic Reviews of Interventions. Meta-analyses were performed on blood pressure, Pittsburgh Sleep Quality Index (PSQI), the efficacy rate of diagnostic and therapeutic criteria for traditional Chinese medicine syndromes (DTCTCMS), and the efficacy rate of guidelines for traditional Chinese medicine (new drug) clinical research (GTCMCR) by Revman 5.3.0. Results. A total of 18 randomized controlled trials with 1685 patients were identified. Compared with a control or comparison group, pooled metaanalyses showed that auricular acupressure significantly improved systolic blood pressure (MD $=-15.05,95 \%$ CI $(-18.49,-11.61)$, $P<0.00001)$, diastolic blood pressure $(\mathrm{MD}=-8.41,95 \% \mathrm{CI}(-11.33,-5.48), P<0.00001)$, PSQI $(\mathrm{MD}=-2.37,95 \% \mathrm{CI}(-4.64$, $-0.10), P=0.04)$, the efficacy rate of DTCTCMS (RR $=1.63,95 \%$ CI $(1.16,2.28), P=0.004)$, and the efficacy rate of GTCMCR $(\mathrm{RR}=1.25,95 \% \mathrm{CI}(1.12,1.38))$. Conclusions. The results demonstrated a favorable effect of auricular acupressure to reduce blood pressure and improve sleep in patients with hypertension and insomnia. Further studies to better understand the acupoints and intervention times of auricular acupressure are warranted.

\section{Introduction}

The incidence of hypertension is gradually increasing due to changes in living conditions and habits. A significant proportion of hypertensive patients are accompanied by insomnia [1]. Evidence suggests that the shortening of sleep time is closely linked to hypertension in young, middle-aged [2], and elderly patients [3]. Shortened sleep times may affect hypertension in many ways, with effects on the autonomic nervous system $[4,5]$, inflammatory factors $[6,7]$, and the quality of life of patients. Vgontzas et al. believed that sustained insomnia may even become an independent risk factor for hypertension [8]. Antihypertensives combined with sleeping drugs comprise the current mainstream treatment [9], but sleeping pills are often not accepted by patients because they may develop dependency.

As an essential branch of traditional Chinese medicine (TCM) treatment, auricular acupressure has been widely used in various diseases, such as obesity [10], anxiety [11], pain [12], and insomnia [13]. In this context, the efficacy of auricular acupressure on hypertension and insomnia has gradually been recognized, and many researchers have also explored this linkage. However, their results are questionable due to the small sample sizes and different measurement standards in each study. In this study, the therapeutic effects of auricular acupressure on hypertension and insomnia were systematically evaluated, and a meta-analysis was conducted to provide a reference for the treatment of these conditions. 


\section{Method}

The method used in this systematic review has been previously registered in PROSPERO (CRD42020153992), which is available from https://www.crd.york.ac.uk/prospero/.

2.1. Data Sources and Search Strategies. The following databases were searched using a computer: Cochrane Central Register of Controlled Trials (CENTRAL), PubMed, Ovid LWW, Web of Science, Chinese Biomedical Literature Database (CBM), China Knowledge Resource Integrated Database (CNKI), Wanfang Data, and China Science and Technology Journal Database (VIP). The search strategy terms included auricular acupressure, high blood pressure, insomnia, sleep disorders, convulsions, and dizziness. The retrieval time was from the establishment of the database to November 2019, and the references to the included articles were also retroactively searched. An illustrative PubMed search strategy is as follows:

(1) Hypertension OR Blood Pressure, High OR Blood Pressures, High OR High Blood Pressure OR High Blood Pressures

(2) Disorders of Initiating and Maintaining Sleep OR DIMS (Disorders of Initiating and Maintaining Sleep) OR Early Awakening OR Awakening, Early OR Nonorganic Insomnia OR Insomnia, Nonorganic OR Primary Insomnia OR Insomnia, Primary OR Transient Insomnia OR Insomnia, Transient OR Rebound Insomnia OR Insomnia, Rebound OR Secondary Insomnia OR Insomnia, Secondary OR Sleep Initiation Dysfunction OR Dysfunction, Sleep Initiation OR Dysfunctions, Sleep Initiation OR Sleep Initiation Dysfunctions OR Sleeplessness OR Insomnia Disorder OR Insomnia Disorders OR Insomnia OR Insomnias OR Chronic Insomnia OR Insomnia, Chronic OR Psychophysiological Insomnia OR Insomnia, Psychophysiological

(3) Auricular seed pressing OR Auricular point pressing OR Auricular pressing OR Auricular acupoint pressing OR Auricular acupressure OR Auricular seed acupressure OR Auricular point acupressure

(4) (1) and (2) and (3)

2.2. Criteria for considering Studies for This Review. Studies should meet the following inclusion criteria (PICO format). (1) Participants: this refers to patients with a clear diagnosis of hypertension and insomnia. The diagnostic criteria for hypertension are as referred to in China's Guidelines for Prevention and Treatment of Hypertension (2018 Revision) [14]. And the following criteria are referenced in the diagnosis of insomnia: American diagnostic and statistical manual of mental disorders, fifth edition (DSM-V) [15], international classification of diseases-10 (ICD-10) [16], international classification of sleep disorders (ICSD) [17], classification and diagnostic criteria for Chinese mental disorders (CCDM) [18], the diagnostic and therapeutic criteria for traditional Chinese medicine syndromes (DTCTCMS) [19], guidelines for traditional Chinese medicine (new drug) clinical research (GTCMCR) [20], and other commonly used diagnostic criteria. The age, gender, race, source of case, time of illness, etc. of subjects were not restricted. (2) Interventions: the experimental group was given auricular acupressure, and the manipulation and specific acupoints were not restricted. (3) Control: this refers to any type of control group, including conventional Western medicine, routine nursing, or blank control. (4) Outcomes: at least one of the following scales was required to be included in the evaluation of sleep quality: Pittsburgh Sleep Quality Index (PSQI) [21], the efficiency of the diagnostic and therapeutic criteria for TCM syndromes [19], the efficiency of guidelines for TCM (new drug) clinical research [20], sleep status self-assessment scale [22], or other inferable data mentioning insomnia and auricular acupressure for carrying out meta-analysis; and systolic and diastolic blood pressure were used to evaluate blood pressure. (5) Study type: the type of study was randomized controlled trials.

Exclusion criteria were the following: (1) duplicate literature; (2) incomplete literature information; (3) differences in baseline between groups; (4) no exact efficacy evaluation index.

2.3. Literature Screening and Data Extraction. First, two investigators reviewed the titles and abstracts independently according to the preset inclusion and exclusion criteria, and then they read the full texts after excluding apparently unrelated literature. The final included literature was identified after further screening, and after that, two investigators extracted the data while blinded to each other's review. Finally, the results were cross-checked. The differences were resolved by consensus with a third investigator.

The data extraction included the following aspects: (1) general information: first author, publication year, literature topics, etc.; (2) research characteristics: baseline comparability, sample size, sex ratio, country, intervention measures, treatment course, and follow-up; (3) outcome indicators; and (4) relevant factors for evaluating the risk of bias.

2.4. Assessment of Risk of Bias in Included Studies. Two reviewers independently assessed the risk of bias in accordance with suggested categories listed in the Cochrane Handbook for Systematic Reviews of Interventions [23] and then conducted cross-checking. The differences were resolved by consensus with a third investigator. RevMan5.3.0, provided by the Cochrane Collaboration, was used to created plots demonstrating the risks of bias.

2.5. Statistical Analysis. Rewman 5.3.0 was used for statistical analysis. The mean difference (MD) and 95\% confidence interval $(95 \% \mathrm{CI})$ were used when the outcomes were continuous variables, while the risk ratio (RR) and 95\% CI were used when the outcomes were two categorical variables. The chi-square test and $I^{2}$ statistic were used to check the 
heterogeneity of the results. The fixed-effects model was used when the statistical heterogeneity was small $(P \geq 0.1$, $\left.I^{2}<50 \%\right)$; otherwise, subgroup analyses according to total sample size, intervention time, control type were performed, as well as sensitivity analyses if necessary. Publication bias was estimated with a funnel plot.

\section{Results}

3.1. Literature Search Results. 613 original studies were collected by database searching, and 236 duplicate studies were excluded. After screening the titles and abstracts of the remaining literature, 286 articles were excluded, including case reports, reviews, and irrelevant publications. Then the full texts were read, and another 73 studies were excluded due to their nonconforming interventions, inadequate control groups, and inaccurate evaluation indicators. At last, 18 studies were included [24-41]. The specific screening process and results are displayed in Figure 1.

3.2. Characteristics of the Included Literature. A total of 18 studies were included with a total of 1685 patients. Their basic characteristics are shown in Table 1 . In these 18 studies, the experimental group underwent auricular acupressure, among which 13 studies [24, 27, 29-32, 34, 35, 37, 39, 41] had an intervention time of $\leq 15$ days, and 5 studies $[25,26,33,36,38]$ had an intervention time of $>15$ days. The intervention measures of the control groups were as follows: routine nursing was used in 8 studies [28, 30, 31, 33, 34, 37-39], conventional Western medicine was used in 8 studies $[24-27,29,32,36,41]$, and no intervention was used in 2 studies $[35,40]$. The outcomes included were as follows: PSQI was used in 10 studies [26-28, 30-34, 36, 38], the diagnostic and therapeutic criteria for TCM syndromes were used in 3 studies [35, 40, 41], the guidelines for TCM (new drug) clinical research were used in 3 trials [24, 32, 37], Sleep Status SelfAssessment Scale was used in 2 trials $[29,39]$, and an improved Sleep Status Self-Assessment Scale was used in 1 study [25]. Blood pressure was measured in 10 studies $[25,26,28,30,33-36,38,40]$.

3.3. Methodological Quality of the Included Studies. The risk of bias assessment of all included studies is shown in Figures 2 and 3. Two studies that reported the method of randomization in terms of random number table were accorded a low risk of bias in random sequence generation $[24,30]$. Two studies constituted a high risk of bias on account of the alternate allocation method (odd or even hospitalization date) used in these trials [26, 38]. The remaining 14 studies were classified as having an unclear risk of bias because insufficient information was provided [25, 27-29, 31-37, 39-41]. None of 18 studies described the process of allocation concealment in sufficient detail and were judged as having an unclear risk of bias. Due to the obvious difference-whether to use auricular acupressure or not-between the auricular acupressure group and the control group, a blind method could not be used in the participants or administrators in any of the 18 studies [24-41]. One study

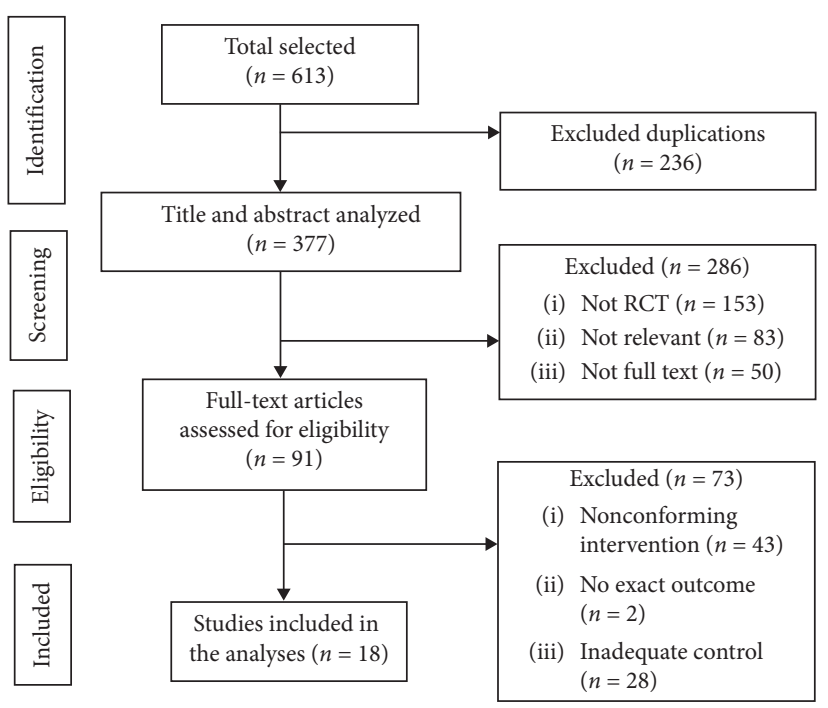

Figure 1: Flow chart of selection process.

[32] was shown to blind its outcome assessment and was graded as low risk of bias. One study [35] that had a high drop-out rate in the control group was judged to have a high risk of bias for incomplete outcome data, and the remaining 17 studies [24-34, 36-41] were classified as having a low risk of bias because all the pre-set outcomes were reported. All studies reported all outcomes listed in their methods section and were graded as low risk of bias for selective reporting. The data necessary for judging the risk of other biases were insufficient in 18 studies [24-41].

\section{Outcomes}

\subsection{Outcomes Related to Blood Pressure}

4.1.1. Systolic Blood Pressure. Systolic blood pressure was examined in 10 articles $[25,26,28,30,33-36,38,40]$. The pooled results showed that auricular acupressure significantly reduced systolic blood pressure $(\mathrm{MD}=-15.05,95 \%$ CI: $[-18.49,-11.61], P<0.00001)$ (Figure 4). Given the high heterogeneity $\left(I^{2}=93 \%, P<0.00001\right)$, sensitivity analyses were performed to explore potential sources of heterogeneity, and the results did not change substantively. The heterogeneity ranged from $92 \%$ to $94 \%$. Then, subgroup analyses were conducted based on total sample size $(\leq 80$ cases and $>80$ cases), comparison method (auricular acupressure plus antihypertensive drugs vs. antihypertensive drugs, and auricular acupressure $v s$. antihypertensive drugs), and intervention time ( $\leq 15$ days and $>15$ days). The results showed a significant difference of heterogeneity in subgroups of comparison method, indicating that the difference of the comparison method was partly the reason why there was severe heterogeneity in the overall analysis (Table 2).

4.1.2. Diastolic Blood Pressure. Ten studies [25, 26, 28, 30, 33-36, 38, 40] reported diastolic blood pressure levels. The pooled result also showed a significant difference between auricular acupressure and the control group in reducing 
TABLE 1: Characteristics of included studies.

\begin{tabular}{|c|c|c|c|c|c|c|}
\hline Author, year & Participants & $\begin{array}{l}\text { No. }(\mathrm{T} / \\
\mathrm{C})\end{array}$ & Main acupoints & $\begin{array}{l}\text { Intervention } \\
\text { time (days) }\end{array}$ & $\begin{array}{l}\text { Control } \\
\text { type }\end{array}$ & $\begin{array}{l}\text { Outcome } \\
\text { measures }\end{array}$ \\
\hline Shang, 2015 & $\begin{array}{l}\text { Middle aged and elderly patients } \\
\text { with hypertension and insomnia }\end{array}$ & $148 / 150$ & $\begin{array}{c}\text { Jiangyagou, Shenmen, heart, } \\
\text { endocrine, Jiaogan, and } \\
\text { Pizhixia }\end{array}$ & 28 & I & (1) (2) (3) \\
\hline Lin, 2018 & $\begin{array}{c}\text { Young and middle-aged } \\
\text { patients with hypertension and } \\
\text { insomnia }\end{array}$ & $25 / 25$ & Heart, kidney, and liver & 6 & II & (1) (6) \\
\hline Zhang, 2018 & $\begin{array}{l}\text { Patients with hypertension and } \\
\text { insomnia }\end{array}$ & $36 / 36$ & $\begin{array}{l}\text { Jiangyagou, Shenmen, heart, } \\
\text { brain, kidney, liver, and spleen }\end{array}$ & 18 & II & (5) \\
\hline Zhang, 2019 & $\begin{array}{l}\text { Patients with hypertension and } \\
\text { insomnia }\end{array}$ & $43 / 43$ & $\begin{array}{c}\text { Jiangyagou, Shenmen, Sanjiao, } \\
\text { Jiaogan, and Pizhixia }\end{array}$ & 15 & II & (2) (3) (7) \\
\hline Gao, 2015 & $\begin{array}{c}\text { Patients with hypertension and } \\
\text { insomnia }\end{array}$ & $30 / 30$ & $\begin{array}{l}\text { Heart, kidney, brain, Shenmen, } \\
\text { and Jiangyagou }\end{array}$ & 15 & I & (7) \\
\hline Wang, 2018 & $\begin{array}{l}\text { Patients with grades } 1 \text { and } 2 \\
\text { hypertension and insomnia }\end{array}$ & $40 / 40$ & $\begin{array}{l}\text { Liver, kidney, Jiaogan, } \\
\text { Shenmen, heart, and } \\
\text { Jiangyagou }\end{array}$ & 28 & I & (1) (2) (3) \\
\hline Wang, 2016 & $\begin{array}{c}\text { Patients with grade } 1 \\
\text { hypertension and insomnia }\end{array}$ & $30 / 30$ & $\begin{array}{l}\text { Pizhixia, Jiaogan, Shenmen, } \\
\text { and Jiangyagou }\end{array}$ & 14 & II & (1) (2) (3) (6) \\
\hline Zhu, 2017 & $\begin{array}{c}\text { Patients with hypertension and } \\
\text { insomnia }\end{array}$ & $72 / 72$ & $\begin{array}{l}\text { Jiaogan, Shenmen, Jiangyagou, } \\
\text { heart, liver, and kidney }\end{array}$ & 28 & I & (1) (2) (3) \\
\hline Li, 2017 & $\begin{array}{l}\text { Patients with grades } 1 \text { and } 2 \\
\text { hypertension and insomnia }\end{array}$ & $32 / 33$ & $\begin{array}{l}\text { Jiaogan, Shenmen, Pizhixia, } \\
\text { heart, and liver }\end{array}$ & 14 & I & (1) (2) (3) \\
\hline Xiao, 2014 & $\begin{array}{c}\text { Patients with hypertension and } \\
\text { insomnia }\end{array}$ & $25 / 25$ & $\begin{array}{l}\text { Jiaogan, Shenmen, Pizhixia, } \\
\text { heart, and endocrine }\end{array}$ & 15 & III & (2) (3) (4) \\
\hline Liu, 2018 & $\begin{array}{l}\text { Patients with hypertension and } \\
\text { insomnia }\end{array}$ & $60 / 60$ & $\begin{array}{c}\text { Heart, Jiaogan, Shenmen, and } \\
\text { Jiangyagou }\end{array}$ & 10 & I & (1) \\
\hline Qian, 2019 & $\begin{array}{c}\text { Elderly patients with } \\
\text { hypertension and insomnia }\end{array}$ & $30 / 30$ & Spleen, liver, Shenmen, heart & 14 & II & (1) \\
\hline Liu, 2019 & $\begin{array}{l}\text { Elderly patients with } \\
\text { hypertension and insomnia }\end{array}$ & $30 / 30$ & $\begin{array}{l}\text { Heart, Jiaogan, Shenmen, } \\
\text { endocrine, Chuiqian, and } \\
\text { minor points }\end{array}$ & 10 & I & (5) \\
\hline Ruan, 2019 & $\begin{array}{l}\text { Patients with hypertension and } \\
\text { insomnia }\end{array}$ & $38 / 38$ & $\begin{array}{c}\text { Heart, liver, kidney, spleen, } \\
\text { Jiangyagou }\end{array}$ & 30 & II & (1) (2) (3) \\
\hline Bao, 2019 & $\begin{array}{c}\text { Patients with hypertension and } \\
\text { insomnia }\end{array}$ & $52 / 52$ & $\begin{array}{c}\text { Heart, liver, kidney, spleen, } \\
\text { and Jiangyagou }\end{array}$ & Unclear & I & (1) (2) (3) \\
\hline Zhang, 2016 & $\begin{array}{c}\text { Patients with hypertension and } \\
\text { insomnia }\end{array}$ & $40 / 40$ & $\begin{array}{c}\text { Heart, liver, kidney, spleen, } \\
\text { and Jiangyagou }\end{array}$ & 25 & III & (2) (3) (4) \\
\hline Qiao, 2014 & $\begin{array}{l}\text { Patients with grade } 1 \\
\text { hypertension and insomnia }\end{array}$ & $30 / 30$ & $\begin{array}{l}\text { Liver, kidney, Pizhixia, } \\
\text { Jiangyagou, endocrine, and } \\
\text { Shenmen }\end{array}$ & 15 & II & (8) (4) \\
\hline Zhang, 2019 & $\begin{array}{l}\text { Patients with hypertension and } \\
\text { insomnia }\end{array}$ & $80 / 80$ & $\begin{array}{l}\text { Jiaogan, Shenmen, Jiangyagou, } \\
\text { and heart }\end{array}$ & 15 & II & (6) \\
\hline
\end{tabular}

(1): PSQI; (2): SBP; (3): DBP; (4): the diagnostic and therapeutic criteria for TCM syndromes; (5): Self-Made Sleep Status Self-Assessment Scale; (6): guidelines for TCM (new drug) clinical research; (7): Sleep Status Self-Assessment Scale. I: routine nursing; II: conventional Western medicine; III: no intervention.

diastolic blood pressure $(\mathrm{MD}=-8.41,95 \% \mathrm{CI}:[-11.33$, -5.48 ], $P<0.00001)$, with high heterogeneity $\left(I^{2}=94 \%\right.$, $P<0.00001$ ) (Figure 5). Then, we carried out sensitivity analyses, and the heterogeneity remained high (ranged from $93 \%$ to $95 \%$ ). Thus, subgroup analyses based on total sample size ( $\leq 80$ cases and $>80$ cases), comparison method (auricular acupressure plus antihypertensive drugs vs. antihypertensive drugs, and auricular acupressure vs. antihypertensive drugs), and intervention time ( $\leq 15$ days and $>15$ days) were conducted. A significant difference in heterogeneity was found in the subgroup of comparison method, indicating that the difference of comparison method was partially the reason for severe heterogeneity. The detailed results are shown in Table 3.

\subsection{Relevant Measures Related to Insomnia}

4.2.1. PSQI. A total of 10 articles with 1057 patients [26-28, 30-34, 36, 38] used PSQI scores as an outcome. The pooled result suggested that the auricular acupressure was superior to the control group in the improvement of the PSQI (MD $=-2.37,95 \%$ CI: $[-4.64,-0.10], P=0.04)$, with high heterogeneity $\left(I^{2}=98 \%, P<0.00001\right)$ (Figure 6). So, we carried out sensitivity analyses and subgroup analyses to investigate the potential sources of heterogeneity. The heterogeneity did not change after the studies were removed one by one, which means that the heterogeneity result was stable. We also carried out subgroup analyses according to the total sample $\operatorname{size}(\leq 80$ cases and $>80$ 


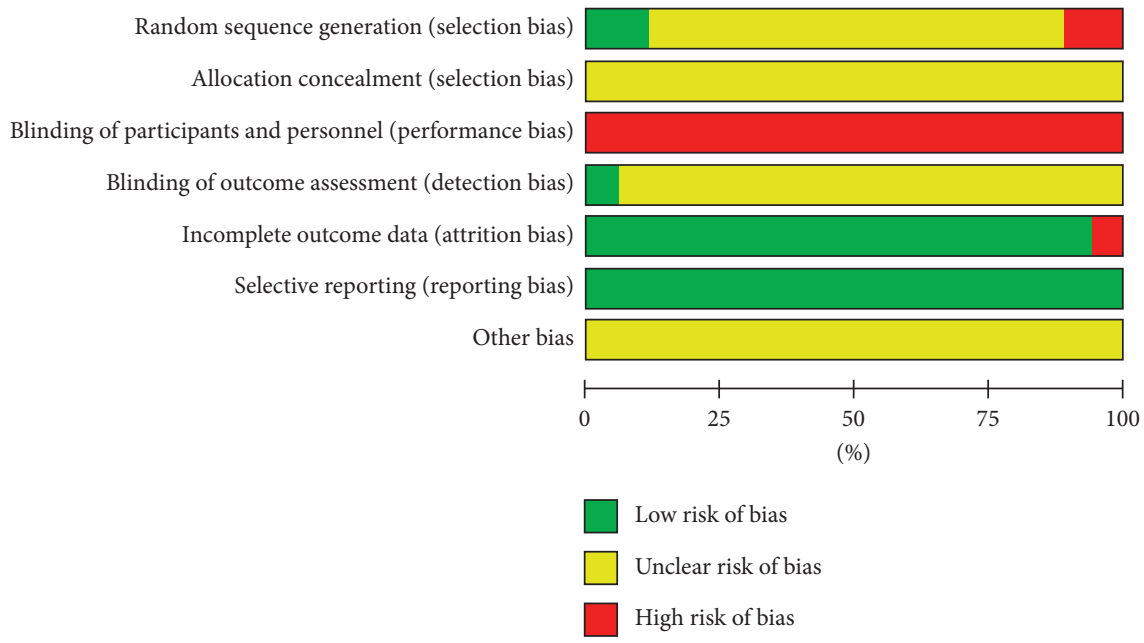

FIgURE 2: Risk of bias graph.

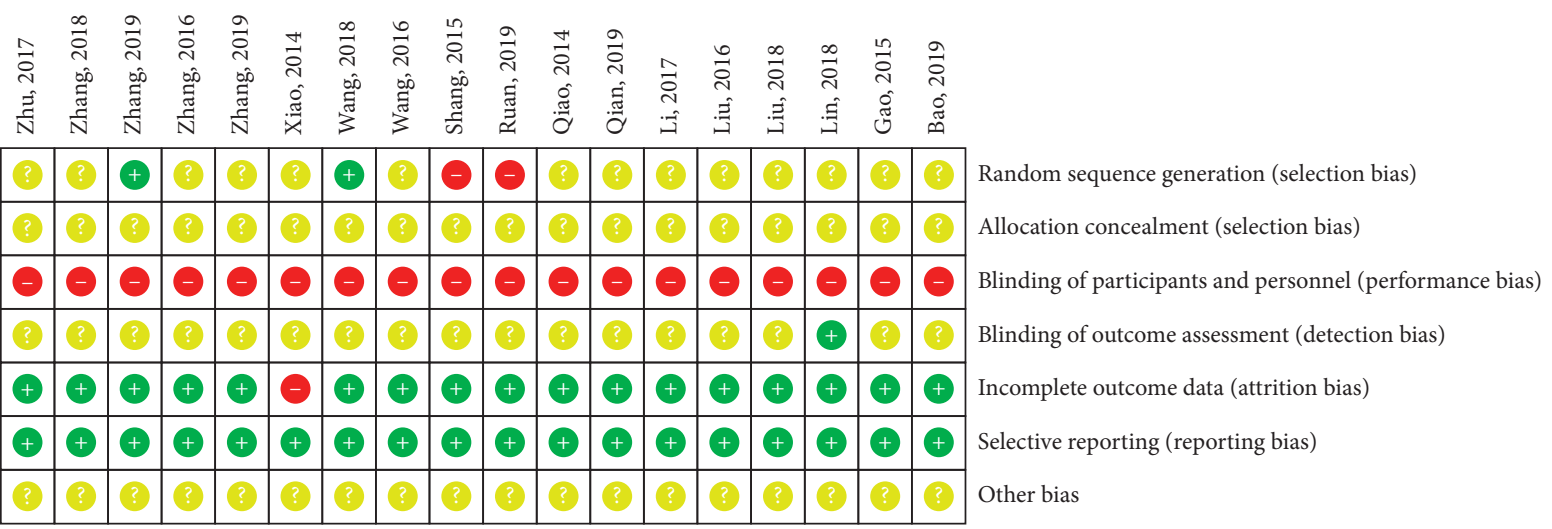

FiguRE 3: Risk of bias summary.

\begin{tabular}{|c|c|c|c|c|c|c|c|c|c|c|c|c|}
\hline \multirow{3}{*}{$\begin{array}{l}\text { Study or subgroup } \\
\text { Bao, } 2019\end{array}$} & \multicolumn{3}{|c|}{ Auricular acupressure } & \multicolumn{3}{|c|}{ Control } & \multirow{2}{*}{$\begin{array}{c}\text { Weight } \\
(\%)\end{array}$} & \multirow{2}{*}{$\begin{array}{c}\text { Mean difference } \\
\text { IV, random, 95\% CI }\end{array}$} & \multirow{2}{*}{\multicolumn{4}{|c|}{$\begin{array}{l}\text { Mean difference } \\
\text { IV, random, } 95 \% \mathrm{CI}\end{array}$}} \\
\hline & Mean & SD & Total & Mean & $\mathrm{SD}$ & Total & & & & & & \\
\hline & 114.46 & 12.55 & 52 & 136.06 & 15.79 & 52 & 8.6 & $-21.60[-27.08,-16.12]$ & $\square$ & & & \\
\hline Li, 2017 & 138.6 & 7.8 & 32 & 142.9 & 9.2 & 33 & 9.5 & $-4.30[-8.44,-0.16]$ & & & & \\
\hline Ruan, 2019 & 124.18 & 5.76 & 38 & 147.92 & 6.28 & 38 & 10.3 & $-23.74[-26.45,-21.03]$ & -- & & & \\
\hline Shang, 2015 & 118.56 & 6.53 & 150 & 133.06 & 12.73 & 148 & 10.5 & $-14.50[-16.80,-12.20]$ & & & & \\
\hline Wang, 2016 & 130.43 & 7.65 & 30 & 135.57 & 7.87 & 30 & 9.6 & $-5.14[-9.07,-1.21]$ & & & & \\
\hline Wang, 2018 & 128.49 & 7.38 & 40 & 139.48 & 8.27 & 40 & 9.9 & $-10.99[-14.42,-7.56]$ & & - & & \\
\hline Xiao, 2014 & 125.2 & 5.3 & 30 & 143.2 & 4.6 & 30 & 10.4 & $-18.00[-20.51,-15.49]$ & $\multimap-$ & & & \\
\hline Zhang, 2019 & $121.4 \mathrm{t}$ & 5.4 & 43 & 139.8 & 6.7 & 43 & 10.3 & $-18.40[-20.97,-15.83]$ & 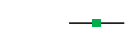 & & & \\
\hline Zhang, 2016 & 125.31 & 4.36 & 40 & 145.32 & 5.64 & 40 & 10.5 & $-20.01[-22.22,-17.80]$ & -- & & & \\
\hline Zhu, 2017 & 118.43 & 6.12 & 72 & 131.56 & 7.58 & 72 & 10.5 & $-13.13[-15.38,-10.88]$ & & - & & \\
\hline Total (95\% CI) & & & 527 & & & 526 & 100.0 & $-15.05[-18.49,-11.61]$ & & & & \\
\hline \multicolumn{9}{|c|}{ Heterogeneity: $\operatorname{tau}^{2}=28.03 ; \mathrm{chi}^{2}=129.85, d f=9(P<0.00001) ; I^{2}=93 \%$} & & & $T$ & T \\
\hline \multicolumn{9}{|c|}{ Test for overall effect: $Z=8.58(P<0.00001)$} & -20 & -10 & 10 & 20 \\
\hline & & & & & & & & & $\begin{array}{r}\mathrm{Fa} \\
\text { (auricular }\end{array}$ & $\begin{array}{l}\text { urs } \\
\text { cupressure) }\end{array}$ & & $\begin{array}{l}\text { Favours } \\
\text { (control) }\end{array}$ \\
\hline
\end{tabular}

FIgURE 4: Forest plot of the comparison between auricular acupressure and the control group for the outcome systolic blood pressure.

cases), intervention time( $\leq 15$ days and $>15$ days $)$, and comparison method(auricular acupressure plus routine nursing $v s$. routine nursing, and auricular acupressure plus hypnotics $v s$. hypnotics). Subgroup analyses showed significant results between subgroups of total sample size $\leq 80$ cases and $>80$ cases, which may be partly the reason why there was severe heterogeneity in the overall analysis (Table 4). 
TABLE 2: Subgroup analyses based on various criteria for systolic blood pressure.

\begin{tabular}{|c|c|c|c|c|}
\hline Subgroup & $n$ & $\mathrm{MD}(95 \% \mathrm{CI})$ & Heterogeneity (\%) & $P$ value \\
\hline \multicolumn{5}{|l|}{ Total sample size } \\
\hline$>80$ & 6 & $-16.33[-19.45,-13.22]$ & 79 & $P<0.00001$ \\
\hline$\leq 80$ & 4 & $-13.85[-19.67,-8.04]$ & 96 & $P<0.00001$ \\
\hline \multicolumn{5}{|l|}{ Intervention time } \\
\hline$\leq 15$ days & 4 & $-11.62[-18.75,-4.50]$ & 95 & $P<0.00001$ \\
\hline$>15$ days & 5 & $-16.52[-20.81,-12.22]$ & 93 & $P<0.00001$ \\
\hline \multicolumn{5}{|l|}{ Control type } \\
\hline $\mathrm{AP}+\mathrm{AHDs}$ vs. AHDs & 7 & $-14.42[-19.16,-9.68]$ & 94 & $P<0.00001$ \\
\hline AP vs. no intervention & 2 & $-19.10[-21.06,-17.14]$ & 28 & $P=0.24$ \\
\hline
\end{tabular}

AP: auricular acupressure; AHDs: antihypertensive drugs.

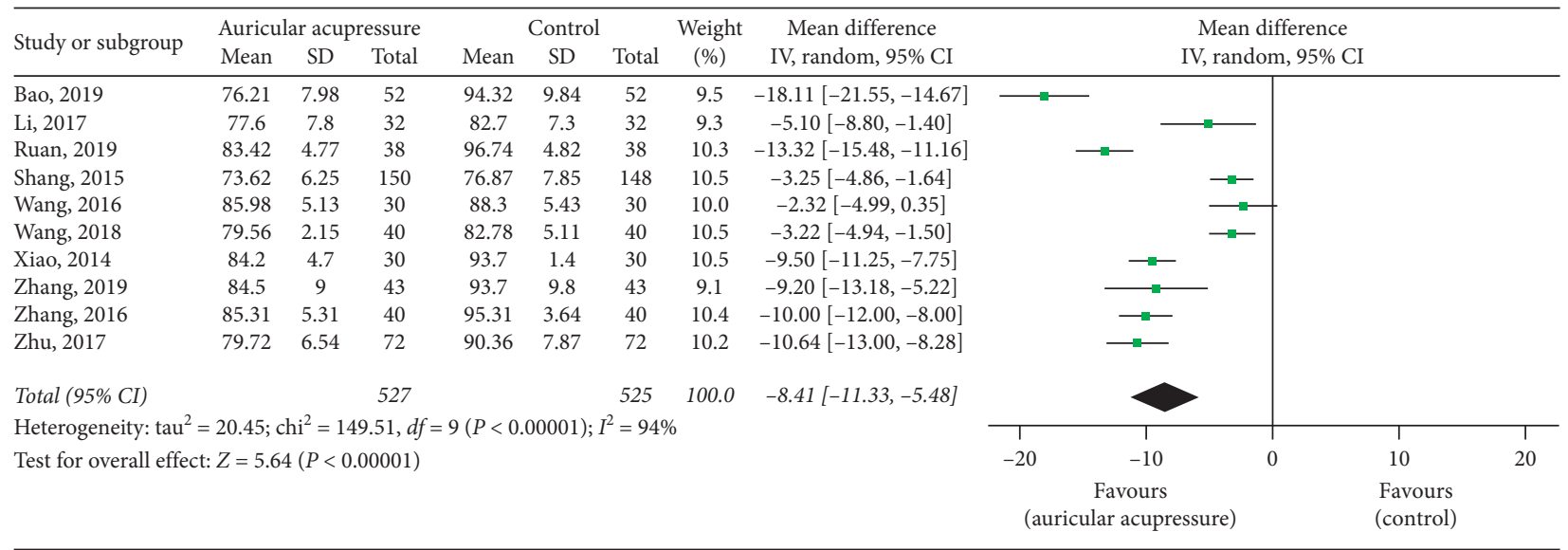

FIGURE 5: Forest plot of the comparison between auricular acupressure and the control group for the outcome diastolic blood pressure.

TABLE 3: Subgroup analyses based on various criteria for diastolic blood pressure.

\begin{tabular}{|c|c|c|c|c|}
\hline Subgroup & $n$ & MD $(95 \% \mathrm{CI})$ & Heterogeneity (\%) & $P$ value \\
\hline $\begin{array}{l}\text { Total sample size } \\
\leq 80 \\
>80\end{array}$ & $\begin{array}{l}6 \\
4\end{array}$ & $\begin{array}{c}-7.31[-10.82,-3.79] \\
-10.21[-16.56,-3.85]\end{array}$ & $\begin{array}{l}94 \\
96\end{array}$ & $\begin{array}{l}P<0.00001 \\
P<0.00001\end{array}$ \\
\hline $\begin{array}{l}\text { Intervention time } \\
\leq 15 \text { days } \\
>15 \text { days }\end{array}$ & $\begin{array}{l}4 \\
5 \\
\end{array}$ & $\begin{array}{l}-6.54[-10.37,-2.70] \\
-8.04[-12.14,-3.94] \\
\end{array}$ & $\begin{array}{l}86 \\
96 \\
\end{array}$ & $\begin{array}{l}P<0.00001 \\
P<0.00001\end{array}$ \\
\hline $\begin{array}{l}\text { Control type } \\
\text { AP + AHDs vs. AHDs } \\
\text { AP vs. no intervention }\end{array}$ & $\begin{array}{l}7 \\
2\end{array}$ & $\begin{array}{l}-8.08[-11.82,-4.33] \\
-9.72[-11.04,-8.40]\end{array}$ & $\begin{array}{c}95 \\
0\end{array}$ & $\begin{array}{c}P<0.00001 \\
P=0.71\end{array}$ \\
\hline
\end{tabular}

AP: Auricular acupressure; AHDs: Antihypertensive drugs.

In addition, the pooled results of subgroup analyses showed significant improvement of PSQI in auricular acupressure compared to the control group for intervention time $\leq 15$ days $(\mathrm{MD}=-4.16,95 \% \mathrm{CI}:[-6.20,-2.13]$, $P<0.0001)$ rather than intervention time $>15$ days $(\mathrm{MD}=-0.12,95 \% \mathrm{CI}:[-4.56,4.32], P=0.96)$, as well as the comparison method of auricular acupressure plus hypnotics vs. hypnotics $(\mathrm{MD}=-4.67,95 \% \mathrm{CI}: \quad[-7.09,-2.25]$, $P=0.00002)$ rather than the method of auricular acupressure plus routine nursing $v$ s. routine nursing $(\mathrm{MD}=-0.71$, 95\% CI: $[-3.86,2.43], P=0.66)$. However, the heterogeneity of these subgroups was still very high, which may be caused by the low methodological quality of the included studies.
4.2.2. Efficiency Rate of the Diagnostic and Therapeutic Criteria for TCM Syndromes. The efficiency rate of the diagnostic and therapeutic criteria for TCM syndromes was used in 3 studies [35, 40, 41]. These criteria, promulgated by the State Administration of Traditional Chinese Medicine of China, divides the improvement of insomnia into three levels, that is, cure: sleep returned to normal or sleep time reached 6 hours; improvement: insomnia was significantly improved or sleep time increased by more than 3 hours; ineffectiveness: insomnia did not improve. Effective cases are a summary of cured and improved cases. A random effect model was used for meta-analysis due to high heterogeneity among these studies $\left(I^{2}=66 \%\right.$, $P=0.05)$. The results showed that participants who received 


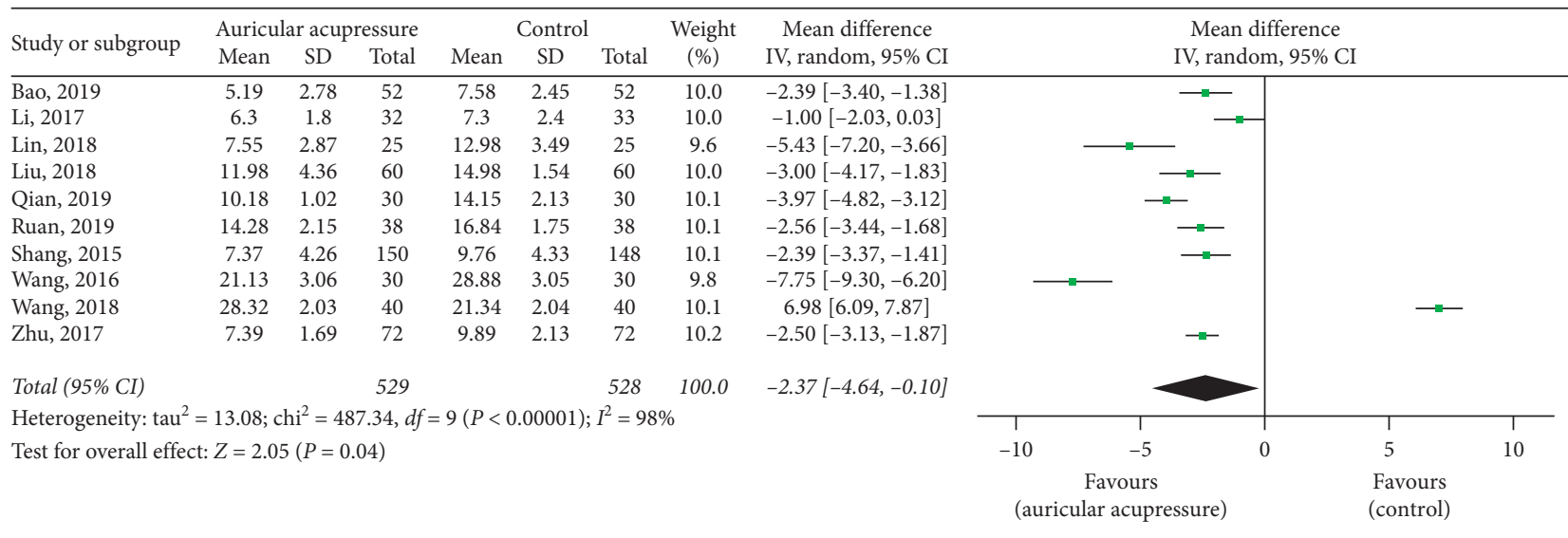

FIGURE 6: Forest plot of the comparison between the auricular acupressure and the control group for the outcome PSQI.

TABLE 4: Subgroup analyses based on various criteria for PSQI.

\begin{tabular}{|c|c|c|c|c|}
\hline Subgroup & $n$ & MD (95\% CI) & Heterogeneity (\%) & $P$ value \\
\hline $\begin{array}{l}\text { Total sample size } \\
\leq 80 \\
>80 \\
\end{array}$ & $\begin{array}{l}4 \\
6 \\
\end{array}$ & $\begin{array}{l}-2.96[-2.96,-2.09] \\
-2.26[-6.42,-1.89]\end{array}$ & $\begin{array}{c}0 \\
99 \\
\end{array}$ & $\begin{array}{c}P=0.85 \\
P<0.00001\end{array}$ \\
\hline $\begin{array}{l}\text { Intervention time } \\
\leq 15 \text { days } \\
>15 \text { days } \\
\end{array}$ & $\begin{array}{l}5 \\
4 \\
\end{array}$ & $\begin{array}{c}-4.16[-6.20,-2.13] \\
-0.12[-12.14,-4.32] \\
\end{array}$ & $\begin{array}{l}93 \\
99 \\
\end{array}$ & $\begin{array}{l}P<0.00001 \\
P<0.00001 \\
\end{array}$ \\
\hline $\begin{array}{l}\text { Control type } \\
\text { AP + AHDs vs. AHDs } \\
\text { AP vs. no intervention }\end{array}$ & $\begin{array}{l}6 \\
3 \\
\end{array}$ & $\begin{array}{l}-0.71[-3.86,-2.43] \\
-4.67[-7.09,-2.25]\end{array}$ & $\begin{array}{l}99 \\
84 \\
\end{array}$ & $\begin{array}{l}P<0.00001 \\
P<0.00001 \\
\end{array}$ \\
\hline
\end{tabular}

AP: auricular acupressure; RN: routine nursing.

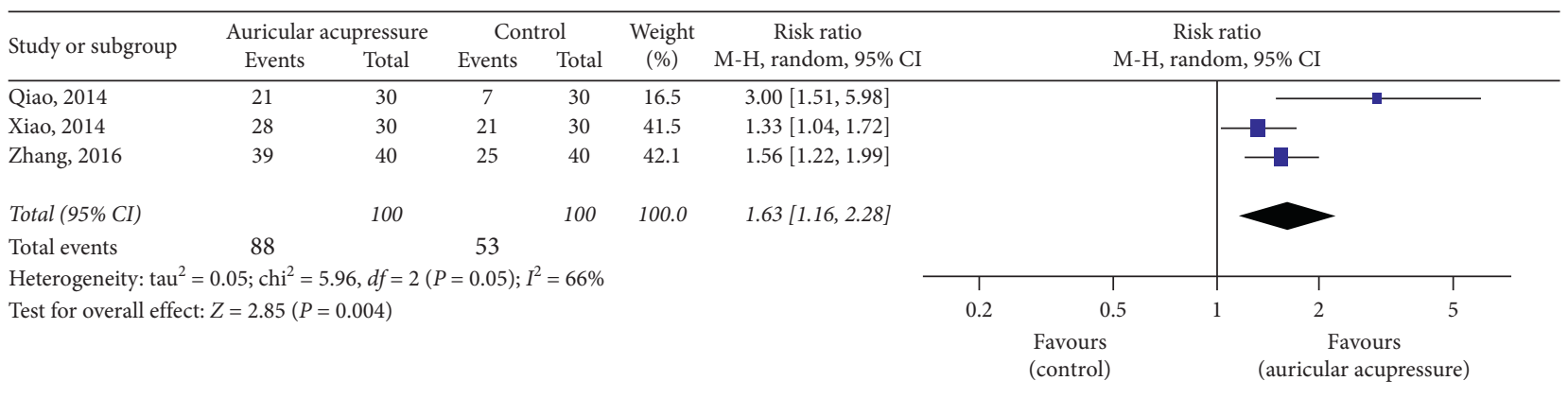

FIGURE 7: Forest plot of the comparison between auricular acupressure and the control group for the efficiency rate of the diagnostic and therapeutic criteria for TCM syndromes.

auricular acupressure had more sleep improvement compared to the control group ( $\mathrm{RR}=1.63,95 \% \mathrm{CI}$ : $[1.16,2.28], P<0.0001)$ (Figure 7). Then, we carried out sensitivity analyses and found that the heterogeneity changed significantly $\left(I^{2}=66 \%, P=0.50\right)$ after removing one set of data [41]. It seemed that this study, showing that auricular acupressure had more significant effects than other studies, may be the potential source of heterogeneity. However, when we looked up the study again, we failed to find differences in methodology and other aspects.

4.2.3. Efficiency Rate of the Guidelines for TCM (New Drug) Clinical Research. The guidelines for TCM (new drug) clinical research were used in 3 studies [24, 32, 37]. These guidelines, issued by the Chinese Ministry of Health, divides the improvement of insomnia into four levels, that is, cure: noticeable improvement in sleep quality or effective sleep time over 6 hours; significant effectiveness: moderate improvement in sleep quality or effective sleep time up to 3-6 hours; effectiveness: insignificant improvement in sleep quality or sleep time less than 3 hours; ineffectiveness: no improvement in sleep quality or the effective sleep time is not extended. A fixed effects model was used for meta-analysis due to low levels of heterogeneity among these studies $\left(I^{2}=0 \%, P=0.50\right)$. The combined result was statistically significant $(\mathrm{RR}=1.25,95 \% \mathrm{CI}$ : $[1.12,1.38], P<0.0001)$ compared to the control group, showing favorable effects of auricular acupressure in sleep improvement (Figure 8). 


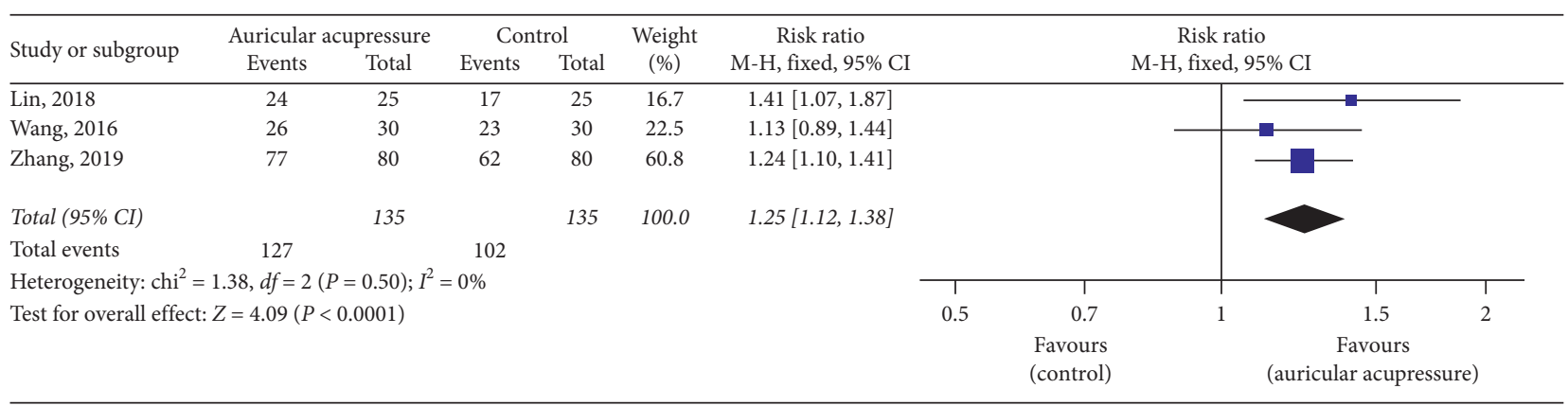

FIGURE 8: Forest plot of the comparison between auricular acupressure and the control group for the efficiency rate of the guidelines for TCM (new drug) clinical research.

4.2.4. Sleep Status Self-Assessment Scale. Sleep Status SelfAssessment Scale was used in 2 studies [29, 39], while a selfmade Sleep Quality Self-Assessment Scale was used in 1 study [25]. The meta-analysis could not be carried out due to the inconsistency of the data and evaluation standards. However, all 3 studies suggested that the experimental groups were more effective than the control groups in improving sleep quality ( $P<0.05$ for all 3 groups).

4.3. Publication Bias. The funnel plot was drawn based on studies that included the outcome of systolic blood pressure. Six studies [26, 30, 33-36] were significantly asymmetrical, suggesting that publication bias might exist (Figure 9). However, when we looked up these 6 studies again, we did not find differences in methodology and other aspects.

4.4. Safety Monitoring. A description of serious adverse events was not found in the included studies.

\section{Discussion}

A total of 18 articles were included in this systematic review. The key finding from this study showed that auricular acupressure may have positive effects on the treatment of patients with hypertension and insomnia, and it may be an augmentation approach to control blood pressure and improve insomnia.

5.1. Main Results and Analysis. The incidence of hypertension with insomnia is increasing gradually [42]. In China, due to the resistance to sleeping pills and the desire to take Western medicine as little as possible, many patients seek help from TCM, including pharmaceutical and nonpharmacological treatments. Therefore, auricular acupressure is favored because of its simple operation, and patients can press the acupuncture points at any time when they are free, without the aid of a doctor [43]. In China, auricular acupressure, a crucial nonpharmacological treatment method, is often applied in combination with medications to treat individuals with hypertension and insomnia. Some scholars believe that the regulation of auricular acupressure for hypertension and insomnia is affected by the vagus nerve, which regulates neuroendocrine self-balancing [44].

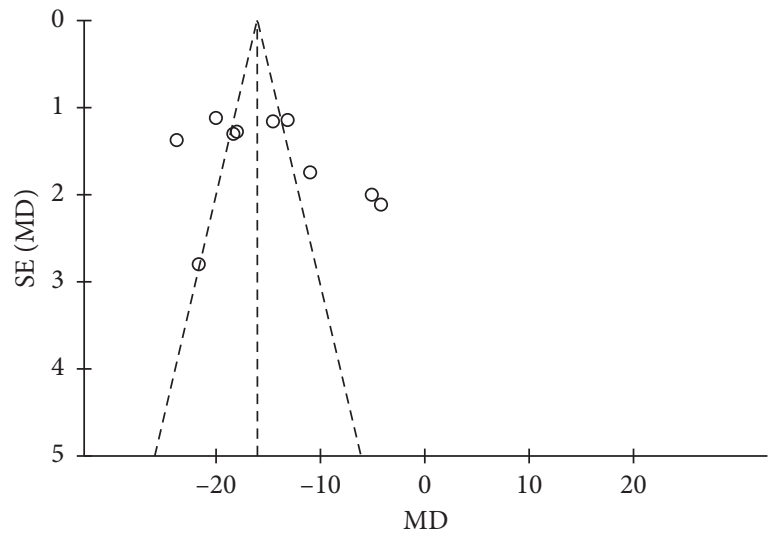

FIgURE 9: Funnel plot of trials comparing systolic blood pressure.

Fallgater recorded the vagal somatosensory-evoked potential from stimulating the ear armor and proposed that this potential originated from the dorsal nucleus of the brainstem nerve. The dorsal nucleus of the brainstem nerve was shown to be synaptic with the hypothalamus and amygdala to regulate insomnia [45]. In our study, we also found that auricular acupressure may be effective in the above two aspects: sleep improvement and blood pressure reduction. We believe that auricular acupressure may be a complementary treatment for hypertension and insomnia, which can be promoted to other countries.

The results of this meta-analysis showed that a significant improvement of insomnia could be seen in the intervention time of $\leq 15$ days and the comparison method of auricular acupressure plus hypnotics vs. hypnotics. At present, there is no randomized controlled trial proving this conclusion. However, Liu and Wang [46] have proposed the concept of "meridian fatigue," which refers to the phenomenon that occurs when a disease cannot be cured with long-term treatment or may even get worse due to the excessive consumption of qi and blood in meridians and the weakening of the functioning of meridians and collaterals. Zhang et al. [47] also believed that inappropriate high-intensity stimulation on acupoints might consume vital qi, thus affecting the disease recovery process. However, the interpretation of these results should be treated with caution in clinical practice. In this meta-analysis, high heterogeneity, a relatively small number of studies, low quality of literature, 
and nonuniform auricular acupressure procedures may have led to this result. A high-quality, well-designed, large-scale trial is still needed to further validate this conclusion.

5.2. Limitations. The overall quality of the included studies was not high, with only 2 studies reporting appropriate randomization methods, and none of the 18 studies mentioned allocation concealment. At the same time, all the participants and administrators cannot be blinded to whether to use auricular acupressure or not, and the data for judging the other biases in all 18 studies were inadequate. In addition, publication bias existed. In the funnel plot, six studies were significantly asymmetrical, where, however, differences in methodology and other aspects cannot be found due to the low quality and inadequate information provided in these studies.

The high heterogeneity of the results cannot be ignored either. We conducted subgroup analyses with respect to intervention time, comparison method, and total sample size. We found that the comparison method and total simple size might partly be the source of heterogeneity. However, they can only explain the heterogeneity to some extent, and there remained substantial unexplained heterogeneity in the pooled results, such as study design and study quality. Although auricular acupressure was the primary intervention method, the specific acupoints and operation methods varied between each study. In addition, the inclusion criteria for each study were slightly different, as some included grade 1 hypertensive patients and some were grade 1 and grade 2 hypertensive patients, while others had unrestricted participation. Therefore, the result that the heterogeneity may come from comparison methods and sample sizes should be interpreted with great caution.

Additionally, the included studies were conducted in Asian countries, so the results lack evidence from Western countries. Chinese and English were the 2 basic search languages, but other languages should be searched to expand the scope as well. Moreover, in terms of sleep improvement, subjective scales were adopted by most of the studies, which were less convincing than the objective indicators. And the evidence on the safety evaluation of auricular point pressing is lacking. All these points need further observation and analysis in future research work.

5.3. Practical Implications. According to our study, auricular acupressure may be effective for hypertension and insomnia, but the potential findings should be interpreted carefully on account of low quality and clinical heterogeneity. Nevertheless, the quantitative analysis of the current research is still a constructive reference for future clinical trials. From a clinical point of view, the development of the standard auricular acupressure process, frequency of the operation, acupoint combination, and duration of treatment of auricular acupressure are urgent problems to be solved.

\section{Conclusion}

Based on current evidence, auricular acupressure may be effective in patients with hypertension and insomnia.
Auricular acupressure can be promoted as a possible alternative method for blood pressure and sleep management in this population. However, due to the limitations of the literature, large-sample, multicenter, well-designed clinical trials are still required. Different acupoints and intervention times may need to be analyzed to further explore the factors affecting the efficacy of the treatment.

\section{Data Availability}

The data used to support the findings of this study are included within the article.

\section{Conflicts of Interest}

The authors declare that they have no conflicts of interest.

\section{Authors' Contributions}

Z-H Z, Y Z, and W-H L contributed to the conception of the study. The manuscript protocol was drafted by $\mathrm{Z}-\mathrm{H} \mathrm{Z}$ and $\mathrm{Y}$ $\mathrm{Z}$ and was revised by $\mathrm{W}-\mathrm{H} \mathrm{L}$. The search strategy was developed by all the authors and performed by Z-H Z and Y Z, who also independently screened the potential studies, extracted data from the included studies, assessed the risk of bias, and completed the data synthesis. $\mathrm{H} \mathrm{L}$ arbitrated in cases of disagreement and ensured the absence of errors. All authors have read and approved the manuscript.

\section{Acknowledgments}

The authors would like to thank Editage (http://www. editage.cn) for English language editing. This work was funded by the National Key Research and Development Program of China (no. 2017YFC1703304) and the National Natural Science Foundation of China (no. 81873204). Funding bodies play an economic support role in research design.

\section{References}

[1] C. J. Bathgate and J. Fernandez-Mendoza, "Insomnia, short sleep duration, and high blood pressure: recent evidence and future directions for the prevention and management of hypertension," Current Hypertension Reports, vol. 20, no. 6, p. 52, 2018.

[2] X. Wu, Y. Sun, K. Niu et al., "Association of self-reported sleep duration and hypertension: results of a Chinese prospective cohort study," Clinical and Experimental Hypertension, vol. 38, no. 6, pp. 514-519, 2016.

[3] J. Fang, A. G. Wheaton, N. L. Keenan, K. J. Greenlund, G. S. Perry, and J. B. Croft, "Association of sleep duration and hypertension among US adults varies by age and sex," American Journal of Hypertension, vol. 25, no. 3, pp. 335-341, 2012.

[4] E. Tobaldini, C. Cogliati, E. M. Fiorelli et al., "One night oncall: sleep deprivation affects cardiac autonomic control and inflammation in physicians," European Journal of Internal Medicine, vol. 24, no. 7, pp. 664-670, 2013.

[5] W. F. Li and Y. Q. Feng, "Clinical progress in prehypertension," Chinese Journal of Hypertension, vol. 26, no. 6, pp. 516-520, 2018. 
[6] A. Syauqy, C. Y. Hsu, H. H. Rau, A. L. Kurniawan et al., "Association of sleep duration and insomnia symptoms with components of metabolic syndrome and inflammation in middle-aged and older adults with metabolic syndrome in Taiwan,” Nutrients, vol. 11, no. 8, 2019.

[7] E. Tobaldini, E. M. Fiorelli, M. Solbiati, G. Costantino, L. Nobili, and N. Montano, "Short sleep duration and cardiometabolic risk: from pathophysiology to clinical evidence," Nature Reviews Cardiology, vol. 16, no. 4, pp. 213-224, 2019.

[8] A. N. Vgontzas, D. Liao, E. O. Bixler, G. P. Chrousos, and A. Vela-Bueno, "Insomnia with objective short sleep duration is associated with a high risk for hypertension," Sleep, vol. 32, no. 4, pp. 491-497, 2009.

[9] S. J. Thomas and D. Calhoun, "Sleep, insomnia, and hypertension: current findings and future directions," Journal of the American Society of Hypertension, vol. 11, no. 2, pp. 122-129, 2017.

[10] L. L. Zhong, W. Kun, T. F. Lam, and S. P. Zhang, "The combination effects of body acupuncture and auricular acupressure compared to sham acupuncture for body weight control: study protocol for a randomized controlled trial," Trials, vol. 17, no. 1, p. 346, 2016.

[11] S.-Y. Kuo, S.-H. Tsai, S.-L. Chen, and Y.-L. Tzeng, “Auricular acupressure relieves anxiety and fatigue, and reduces cortisol levels in post-caesarean section women: a single-blind, randomised controlled study," International Journal of Nursing Studies, vol. 53, pp. 17-26, 2016.

[12] S.-L. Tsai, L. M. Fox, M. Murakami, and J. W. Tsung, "Auricular acupuncture in emergency department treatment of acute pain," Annals of Emergency Medicine, vol. 68, no. 5, pp. 583-585, 2016.

[13] Y. L. Ko, S. C. Lin, and P. C. Lin, "Effect of auricular acupressure for postpartum insomnia: an uncontrolled clinical trial," Journal of Clinical Nursing, vol. 25, no. 3-4, pp. 332-339, 2016.

[14] China Hypertension Alliance, Chinese Society of Cardiology, Chinese Medical Association Hypertension Specialist et al., "China's guidelines for prevention and treatment of hypertension (2018 Revision)," Prevention and Treatment of CardioCerebral-Vascular Disease, vol. 19, no. 1, pp. 1-44, 2019.

[15] American Psychiatric Association, "Diagnostic and statistical manual of mental disorders," in Proceedings of the 5th, American Psychiatric Publishing, San Francisco, CA, USA, May 2013.

[16] A. M. Liu, International Classification of Diseases (ICD-10) Application Guide, China Union Medical University Press, Beijing, China, 2001.

[17] M. J. Sateia, "International classification of sleep disordersthird edition," Chest, vol. 146, no. 5, pp. 1387-1394, 2014.

[18] Psychiatric Association of Chinese Medical Association, Classification and Diagnostic Criteria for Mental Disorders in China (CCMD-2R), Southeast University Press, Nanjing, China, 1995.

[19] State Administration of Traditional Chinese Medicine, "Diagnosis, syndrome classification and curative effect evaluation of insomnia-the Chinese medicine industry standard of the people's Republic of China, diagnostic and efficacy standards for TCM internal medicine diseases (ZY/T001.1-94)," Journal of Liaoning University of Traditional Chinese Medicine, vol. 18, no. 8, p. 247, 2016.

[20] X. Y. Zheng, Guiding Principles for Clinical Research of New Drugs in Traditional Chinese Medicine, China Medical Science and Technology Press, Beijing, China, 2002.
[21] C. Smyth, "The Pittsburgh sleep quality index (PSQI)," Insight-the Journal of the American Society of Ophthalmic Registered Nurses, vol. 25, no. 3, pp. 97-98, 2000.

[22] J. M. Li, "Introduction to the sleep self-assessment scale (SRSS)," Chinese Journal of Health Psychology, vol. 20, no. 12, p. 1851, 2012.

[23] J. P. T. Higgins and S. Green, Cochrane Handbook for Systematic Reviews of Interventions Version 5.1.0, The Cochrane Collaboration, London, UK, 2011.

[24] M. Zhang, "Effect of auricular acupressure on sleep quality in patients with essential hypertension and insomnia," World Latest Medicine Information, vol. 19, no. 77, pp. 191-193, 2019.

[25] H. L. Zhang, "Therapeutic effect of auricular acupressure combined with Western medicine on hypertension," China Practical Medicine, vol. 14, no. 23, pp. 124-125, 2019.

[26] Y. M. Ruan, J. J. He, and C. Y. Zhu, "Observation and nursing study on treatment of essential hypertension with insomnia by auricular pressing," Journal of Electrocardiogram (Electronic Edition), vol. 8, no. 3, pp. 191-192, 2019.

[27] L. Qian, "Observation and nursing of auricular acupressure in treating elder patients with hypertension and insomnia," Special Health, vol. 14, pp. 202-203, 2019.

[28] X. P. Bao, "Observation and nursing analysis of auricular acupressure in treating essential hypertension with insomnia," Clinical Laboratory Journal(Electronic Edition), vol. 8, no. 1, pp. 51-52, 2019.

[29] X. H. Zhang, "Clinical nursing experience of auricular point pressing in treating essential hypertension with insomnia," Electronic Journal of General Stomatology, vol. 5, no. 20, p. 139-142, 2018.

[30] L. L. Wang, Y. Jiang, and Y. C. Z. Yuan, "The effect of auricular point pressing on hypertension with liver-fire hyperactivity syndrome," China Modern Medicine, vol. 25, no. 12, pp. 108-111, 2018.

[31] L. Y. Liu, X. J. Yang, and L. P. Ye, "The effect of auricular acupresure on sleep quality in patients with essential hypertension and insomnia," Chinese and Foreign Medical Research, vol. 16, no. 4, pp. 119-120, 2018.

[32] N. J. Lin, H. Zhang, and Y. P. Lin, "The effect of auricular acupressure on sleep quality in young and middle-aged patients with hypertension and insomnia," Fujian Medical Journal, vol. 40, no. 3, pp. 129-130, 2018.

[33] L. Zhu, J. H. Mei, and X. Q. Liao, "The effect of auricular acupressure on blood pressure and sleep quality in patients with essential hypertension," Chinese Primary Health Care, vol. 31, no. 12, pp. 89-90, 2017.

[34] X. L. Li, X. Y. Zhong, and F. Q. Zhang, "Clinical observation on the efficiency of auricular acupressure on hypertension and insomnia with liver-yang hyperactivity syndrome," Nursing of Integrated Traditional Chinese and Western Medicine, vol. 3, no. 12, pp. 74-76, 2017.

[35] L. L. Zhang, "Clinical observation of the efficiency of auricular acupressure on hypertension and insomnia," Clinical Journal of Chinese Medicine, vol. 8, no. 28, pp. 52-53, 2016.

[36] B. Wang, H. Q. HuangFu, J. Sun, and J. F. Yang, "Clinical observation of the efficiency of auricular acupoint pressing on hypertension and insomnia," Cardiovascular Disease Journal of Integrated Traditional Chinese and Western Medicine, vol. 4, no. 36, pp. 77-79, 2016.

[37] P. Liu, "Study on the effect of auricular acupressure on hypertension and insomnia," China Health Care and Nutrition, vol. 26, no. 19, p. 294, 2016.

[38] S. M. Shang, M. Y. Cheng, and J. F. Cui, "Effect of blood pressure and sleep quality of auricular acupressure on 
hypertension in middle-aged and elderly patients," Modern Clinical Nursing, vol. 14, no. 8, pp. 31-34, 2015.

[39] J. D. Gao, "Study on auricular acupoint pressing on essential hypertension with insomnia," Guide of China Medicine, vol. 13, no. 34, p. 256, 2015.

[40] M. Xiao, B. Y. Chen, and X. J. Lin, "Therapeutic effect of auricular acupuncture on patients with hypertension and insomnia," Guangming Journal of Chinese Medicine, vol. 29, no. 6, pp. 1299-1300, 2014.

[41] J. F. Qiao, S. Y. He, and W. J. Li, "Observation on the effect of auricular acupressure combined with amlodipine on patients with hypertension and sleep disorders," Contemporary Medicine Forum, vol. 12, no. 20, pp. 283-284, 2014.

[42] X. F. Guo, X. Y. Zhang, J. Wang, L. Q. Zheng et al., "Metaanalysis of the relationship between sleep time and hypertension," Chinese Journal of Hypertension, vol. 21, no. 9, pp. 748-754, 2013.

[43] P.-W. Hou, H.-C. Hsu, Y.-W. Lin, N.-Y. Tang, C.-Y. Cheng, and C.-L. Hsieh, "The history, mechanism, and clinical application of auricular therapy in traditional Chinese medicine," Evidence-Based Complementary and Alternative Medicine, vol. 2015, Article ID 495684, 13 pages, 2015.

[44] S. Zhang, S. H. Jia, L. J. Yang, and Z. G. Jin, "Clinical study on acupuncture combined with auricular acupuncture for menopausal insomnia in women with heart-kidney disharmony syndrome," Acupuncture Research, vol. 44, no. 7, pp. 516-519+524, 2019.

[45] A. J. Fallgatter, A.-C. Ehlis, T. M. Ringel, and M. J. Herrmann, "Age effect on far field potentials from the brain stem after transcutaneous vagus nerve stimulation," International Journal of Psychophysiology, vol. 56, no. 1, pp. 37-43, 2005.

[46] X. J. Liu and J. Y. Wang, "Acupuncture and meridian fatigue," Journal of Traditional Chinese Medicine, no. 8, pp. 474-475, 1995.

[47] P. Zhang, X. X. Qu, and Z. B. Liu, "Analysis of the reasons of fatigue phenomenon in meridian and acupoint," China Journal of Traditional Chinese Medicine and Pharmacy, vol. 34, no. 2, pp. 513-515, 2019. 